\title{
Outcomes of Patients with Peripartum Paralysis with Physiatric Management
}

\author{
MS AHMED ${ }^{a}$, MA SHAKOOR ${ }^{b}$
}

\begin{abstract}
Summary:
This prospective experimental study was conducted from $1^{\text {st }}$ July 2008 to $31^{\text {st }}$ December 2009. Out of 33 patients 29 patients completed 6 weeks' scheduled programs. All the patients were housewives with the age from 17 to 45 years with the mean of $27.48 \pm 7.20$ years. Presenting disability of the patients, pretreatment and post treatment Functional Independence Measures (FIM) scores of self-care, sphincter control, transfers and locomotion were recorded and compared. FIM scores for the normal population are-selfcare 42, sphincter control 14, transfer 21, locomotion 14 and the combined scores for the above four motor functions 91. The pre and post-treatment FIM scores of the patients studied were-self-care $15.45 \pm 5.19$ Vs $35.86 \pm 7.67(95 \%$
\end{abstract}

\section{Introduction:}

Peripartum paralysis may be defined as the paralysis during the period from the last month of pregnancy to the end of sixth week after delivery. Peripartum paralysis is not an uncommon disease ${ }^{1}$. Gupta et. al. found that the incidence of neurological disorders in pregnancy and puerperium was fairly high, 584 per 100,000 deliveries. A wide range of neurologic conditions can affect women during pregnancy and puerperium include eclampsia, strokes, epilepsy, benign intracranial hypertension, CNS tumours, Bell's palsy, obstetric pressure palsies, demyelinating diseases of the central/ peripheral nervous system and neuromuscular junction disorders. Patients may also present with secondary neurological disorders such as metabolic encephalopathies secondary to hypoxia-ischaemia, hypoglycemia, hepatic failure, azotemia, hypercalcemia and nervous system disorders secondary to nutritional deficiencies and endocrine dysfunction ${ }^{1}$. It may occur throughout all the three trimesters of the pregnancy, mainly during postpartum period and occasionally

a. Dr. Md. Shaik Ahmed, FCPS, Associate Professor, Department of Physical Medicine, Chittagong Medical College.

b. Dr. MA Shakoor, FCPS, Associate Professor, Department of Physical Medicine BSMMU, Dhaka.

Address of Correspondence: Md. Shaik Ahmed, FCPS, Associate Professor, Department of Physical Medicine, Chittagong Medical College, E-mail: ahmedshaik56@yahoo.com

Received: 27 October, 2011

Accepted: 3 September, 2012
CI -22.42 to -18.40), sphincter control 10.52 \pm 5.04 Vs 13.93 $\pm 0.370(95 \%$ CI -5.32 to -1.51$)$, transfer $5.52 \pm 2.35$ Vs 5.52 \pm 2.35 (95\% CI -12.30 to -9.70), locomotion $3.24 \pm 1.45 \mathrm{Vs}$ $9.65 \pm 3.33(95 \% \mathrm{CI}-7.40$ to -5.42$)$ and the combined scores $34.86 \pm 12.49$ Vs $75.59 \pm 13.95$ (95\% CI -45.22 to -36.22$)$ with $(p=<0.001)$ in all the mentioned motor functions that were examined. The study showed that the physiatric management is effective for patients with peripartum paralysis.

Key words: Peripartum paralysis, Physiatric, Functional Independence Measure (FIM), Activities of daily living (ADL).

(J Bangladesh Coll Phys Surg 2012; 30: 191-194)

before child birth or in the third trimester ${ }^{2}$. Periodic paralysis, hypokalaemia, multiple sclerosis, Charcot marie-tooth disease, lumbar plexopathy, herniated discs, comprssion neuropathy, conversion disorders, acute and chronic inflammatory demyelinating polyneuropathy and so many other causes may cause peripartum paralysis. Paralysis may be mono-neural to wide spread paralysis. Conversion disorder may occur during child birth which is a condition where patients present with neurological symptoms such as numbness, paralysis, or fits, but where no neurological explanation is possible ${ }^{3}$. Neurological and neurosurgical conditions are encountered occasionally during pregnancy, but serious neurological complications of pregnancy are rare. The range of neurological conditions affecting women of reproductive age is extremely broad ${ }^{4,5,6}$. In 1934, postpartum paralysis of a woman with history of normal delivery with different consultant's different diagnosis was reported ${ }^{7}$. Diagnosis of postpartum paralysis is yet not established, but probably it may be due to acute inflammatory demyelinating polyneuropathy (AIDP) ${ }^{8}$. D'Ambrosio et.al. found that though the incidence of AIDP in pregnancy is similar to that in the normal population, only 50 cases of AIDP during pregnancy have been reported ${ }^{9}$. AIDP has been reported during all the three trimesters of pregnancy ${ }^{10}$ and in the post-partum period ${ }^{11}$.

Physiatric management and rehabilitation may improve the functional disability of the patients with peripartum 
paralysis. Functional Independence Measure (FIM) is widely used and accepted as a functional-level assessment tool that evaluates the functional status of patients throughout the rehabilitation process ${ }^{12}$. To see the outcome of physiatric management this study was done using FIM scores which may help to prepare management plans and rehabilitation of the patients suffering from peripartum paralysis.

\section{Methods and Materials:}

This prospective experimental study was conducted in the Department of Physical Medicine and Rehabilitation of Chittagong Medical College Hospital, from $1^{\text {st }}$ July 2008 to $31^{\text {st }}$ December 2009. Patients attended in the department as out-patient or referred for rehabilitation, from obstetrics ward or maternity hospitals to the department with the complaints of paresis or paralysis from last month of pregnancy to post partum period, were included in the study. Informed consent was taken from all the patients. Presenting clinical neurological features and disability of the patients were evaluated. Diagnosis was done mainly from history and clinical examinations. Pretreatment Functional Independence Measures (FIM) scale ${ }^{13}$ of self-care, sphincter control, transfers and locomotion were recorded. The patients included in the study were treated twice weekly, with infra red radiation for 15 minutes, electrical neuromuscular stimulation 30 minutes per session in the department. The strengthening exercises, range of motion exercises, mobilizing exercises and gait retraining were taught to the patients and the care givers of the patients and advised to practice twice daily at home. The patients were followed up weekly for six weeks. Final outcome of the same motor functions were measured and recorded at the end of $6^{\text {th }}$ week with the same FIM scale. The results were compared between baseline recorded zero week with sixth week. Data were analysed with the help of SPSS package program. Results were expressed as frequency, percentages, mean with SD and student's t-test was done for analysis and level of significance was set at 0.001 .

\section{Results:}

Total 33 patients were recorded during the study period of them 29 patients completed 6 weeks scheduled programs. Due to discontinuation of treatment and follow ups 4 patients were dropped out from the study. All the patients were housewives with the age from 17 to 45 years with the mean $27.48 \pm 7.20$ years. Urban patients were $18.2 \%$ and rural $81.8 \%$. Time duration between onset of disease and attendance of the patients for rehabilitation was 3 days to 32 days with an average $11 \pm 7.5$ days. Onset of the disease was mainly post partum $87.9 \%$ and prepartum $12.1 \%$. Associated conditions of the disease were found present in $48.5 \%$ and no association in $51.5 \%$. Most of the patients (72.7\%) were anaemic. Oedema of the patients was found in about $70 \%$ of the patients. Patients of all gravida are affected, majority patients are of $1^{\text {st }}(33.3 \%)$ and $3^{\text {rd }}$ gravida $(36.4 \%)$. Ambulation of all the patients was aided. Paralysis involved mainly both lower limbs 63.6\% and all limbs 33.3\%. Majority of the patients $(66.7 \%)$ had no bladder involvement and others (33.3\%) had indwelling catheter for a short period. Sensory functions of most of the patients $(84.4 \%)$ were intact. Planter reflexes of both sides of all the patients were found normally flexor. Ankle jerks and knee jerks were absent in both side of majority (about $60 \%$ ) of the patients. Biceps and triceps jerks were normal in 54.5\% in both sides, absent in $6.1 \%$ in both sides and weakly present in $39.4 \%$ in both sides. Muscle power of both lower limbs was found up to grade $3 / 5$ in most (90.9\%) of the patients. In both upper limbs muscle power was in grade $4 / 5$ and normal $(5 / 5)$ in $69.7 \%$. Disability in standing, walking and performing normal activities of daily living were found in all the patients.

FIM scores for the normal population (Table IV) areself-care 42, sphincter control 14, transfer 21, locomotion 14 and the combined scores for the above four motor functions was 91. The pre-treatment (Baseline) FIM scores were found for self-care 15.45 \pm 5.19 , sphincter control $10.52 \pm 5.04$, transfer $5.52 \pm$ 2.35, locomotion $3.24 \pm 1.45$ and the combined scores were $34.86 \pm 12.49$. Outcome FIM scores after physiatric management of six weeks were found for selfcare $35.86 \pm 7.67$ with $95 \%$ CI -22.42 to -18.40 , sphincter control $13.93 \pm 0.370$ with $95 \%$ CI -5.32 to 1.51 , transfer $16.52 \pm 4.21$ with $95 \% \mathrm{CI}-12.30$ to 9.70, locomotion $9.65 \pm 3.33$ with CI -7.40 to -5.42 and the combined scores were $75.59 \pm 13.95$ with $95 \%$ CI -45.22 to -36.22 found $(p=<0.001)$.

Table-I

Time period of onset of paralysis $(n=33)$

\begin{tabular}{lcc} 
Period of onset & Frequency & Percentage \\
\hline Third trimester & 1 & 3.0 \\
Immedite to labour & 9 & 27.3 \\
First week of labour & 14 & 42.4 \\
Second week of labour & 7 & 21.2 \\
Beyond second week & 2 & 6.1 \\
\hline Total & 33 & 100 \\
\hline
\end{tabular}


Table-II

\begin{tabular}{lcc}
\multicolumn{3}{c}{ Paralysis involving body parts $(n=33)$} \\
Body parts & Frequency & Percentage \\
\hline Both lower limbs & 21 & 63.6 \\
All limbs & 11 & 33.3 \\
Left lower limb & 1 & 3.0 \\
\hline Total & 33 & 100 \\
\hline
\end{tabular}

Table-III

\begin{tabular}{lcc}
\multicolumn{3}{c}{ Types of disability $(n=33)$} \\
Types of disability & Frequency & Percentage \\
\hline Walking & 6 & 18.2 \\
Standing & 3 & 9.1 \\
ADLs & 24 & 72.7 \\
\hline Total & 33 & 100 \\
\hline
\end{tabular}

Table-IV

Changes of pre-treatment and post-treatment FIM scores ( $n=29)$

\begin{tabular}{lcccccc}
\multicolumn{7}{c}{ Changes of pre-treatment and post-treatment FIM scores $(n=29)$} \\
FIM & Normal & Mean FIM & Mean FIM & \multicolumn{2}{c}{$95 \%$ CI } & P value \\
\cline { 5 - 6 } & FIM score & in W 0 & in W 6 & Lower & Upper & \\
\hline Self-care & 42 & $15.45 \pm 5.19$ & $35.86 \pm 7.67$ & -22.42 & -18.40 & .001 \\
Sphincter control & 14 & $10.52 \pm 5.04$ & $13.93 \pm 0.370$ & -5.32 & -1.51 & .001 \\
Transfer & 21 & $5.52 \pm 2.35$ & $16.52 \pm 4.21$ & -12.30 & -9.70 & .001 \\
Locomotion & 14 & $3.24 \pm 1.45$ & $9.65 \pm 3.33$ & -7.40 & -5.42 & .001 \\
Combined scores & 91 & $34.86 \pm 12.49$ & $75.59 \pm 13.95$ & -45.22 & -36.22 & .001 \\
\hline
\end{tabular}

\section{Discussion:}

The patients included in this study were out-patients, discharged from the hospitals and clinics as diagnosed cases of paralysis during the last month of pregnancy to postpartum period (peripartum) and referred to physical medicine and rehabilitation for physiatric management. Because of the wide variety of neurological conditions might be involved, the diagnosis of diseases, the neuromuscular status and the disability of the patients were evaluated clinically. Many neurological conditions that may be seen during pregnancy were not observed in this study, because of the period of study was relatively short and the sample size was small. As there is no single mode of management of patients with peripartum paralysis, a supportive and physiatric management plan were made for these patients. Cohen Y, et. al. stated in a study of Bell's palsy complicating pregnancy that recovery is usually good but the preferred mode of management of these patients remains undecided; it is usually confined to supportive care ${ }^{14}$. Associated conditions of the disease were found in $48.5 \%$ patients of which $30.3 \%$ suffered from pre-ecclamsia and no association in $51.5 \%$. To WK et. al. found in a study that ecclampsia was the second most common neurological condition suffering from neurological disorders in pregnancy ${ }^{4}$. Patients from $1^{\text {st }}$ through $6^{\text {th }}$ gravida were found to suffer from the disease in this study. Ambulation of the patients was found to affect in almost all the cases. Paralysis or paresis involved mostly both lower limbs (63.6\%) and quadriparesis (33.3\%). One third of the patients (33.3\%) were suffered from bladder involvement like incontinence and retention that were managed with indwelling catheter for short period. During the first attendance, sensory functions of most of the patient's (84.4\%) were found intact and motor functions were mainly impaired in the affected parts. Most of the patients in the study were found disabled in walking, standing, self-care, sphincter control, locomotion, transfer and performing normal activities of daily living.

FIM scores for the normal population were: - self-care 42, sphincter control 14, transfer 21, locomotion 14 and the combined scores for the above four motor functions were 91 .

In comparison to the normal FIM score for self-care 42 , the average score at first attendance of the patients was $15.45 \pm 5.19$, which was much less than the normal score that means the patients were functionally impaired. After physiatric management of six weeks the score was 
$35.86 \pm 7.67(95 \% \mathrm{CI}-22.42$ to -18.40$)$, meaning that the patients' impairment was improving towards normal score of 42. In comparison to the normal FIM score for sphincter control 14 , the average score at first attendance of the patients was $10.52 \pm 5.04$, means that the patients had disability in sphincter control. The resulting score after treatment $13.93 \pm 0.370$ (95\% CI -5.32 to -1.51 ), showed that the sphincter control was near normal score 14. Regarding the normal FIM score for transfer 21, the average score at first attendance of the patients was $5.52 \pm 2.35$, which means that the patients had disability in transfer. The results of physiatric management of six weeks $16.52 \pm 4.21(95 \%$ CI -12.30 to -9.70$)$ out of 21 , showed that the patients' disability in transfer improved significantly. The average of FIM score for locomotion $3.24 \pm 1.45$ out of normally 14 showed that the patients had disability in locomotion. After six weeks of physiatric management FIM score $9.65 \pm 3.33$ (95\% CI -7.40 to -5.42 ) showed that the patients were almost normal in locomotion. In comparison to the normal FIM score of combined motor functions for self-care, sphincter control, transfer, locomotion 91, the average score at the first attendance of the patients was $34.86 \pm$ 12.49. At the end of six weeks physiatric management the score was $75.59 \pm 13.95$ (95\% CI -45.22 to -36.22$)$, which showed the improvement of the patients was significant $(p=<0.001)$. In these comparative results of normal FIM, pre and post treatment motor functional scores conforms that the physiatric management significantly improved the patients suffering from peripartum paralysis. Ottenbacher et. al. showed that rehabilitation improves functional outcomes ${ }^{15}$ which conformed the results of this study. Chung et. al. found that most patients with obstetrical paralysis have some useful functional return ${ }^{16}$ that was proved in this study. $\mathrm{Ng}$ YS et. al. found that rehabilitation improves functional outcomes across a wide range of diagnoses ${ }^{17}$ which also conformed the results of our present study.

\section{Limitations of the study}

Diagnostic investigations like MRI and NCV were not done due to unavailability of specific laboratory facilities and poor economic conditions of majority of the patients.

\section{Conclusion:}

This study shows that physiatric management is effective for the patients suffering from paralysis during pregnancy and puerperium. Further study with large samples and different populations are required to prove the results of this study.

\section{References:}

1. Gupta S, Rohatgi A, Sharma SK, Gurtoo A. A study of neurological disorders during pregnancy and puerperium. Ann Indian Acad Neurol 2006;9:152.

2. Goyal V, Misra BK, Singh S, Prasad K, Behari M. Acute inflammatory demyelinating polyneuropathy in patients with pregnancy. Neurol India 2004; 52:283.

3. The ICD-10 classification of mental and behavioural disorders: clinical descriptions and diagnostic guidelines. Geneva, World Health Organization, 1992.

4. To WK, Cheung RT. Neurological disorders in pregnancy. Hong Kong Med J 1997; 3:400-8.

5. Goldstein PJ. Neurological disorders of pregnancy. New York: Future Publishing, 1986.

6. Donaldson JO. Neurology of pregnancy. 2nd ed. London: 408 HKMJ Vol 3 No 4 December 1997.

7. Abe C. Postpartum paralysis with report of an unususal case. Am. J. Obstet. \& Gynae. 1934; 28:611.

8. Goyal V, Misra BK, Singh S, Prasad K, Behari M. Acute inflammatory demyelinating polyneuropathy in patients with pregnancy. Neurol India 2004; 52:283-4.

9. D’Ambrosio G, De Angelis G. Syndrome de Guillain-Barre au cours de la grossesse. Ren Neurol (Paris) 1985; 141:33.

10. Zeeman GG. A case of acute inflammatory demyelinating polyradiculoneuropathy in early pregnancy. Am J Perinatol 2001;18:213.

11. Gautier PE, Pierre PA, Van Obbergh LJ, Van Steenberge A. Guillain-Barre syndrome after obstetrical epidural analgesia. Reg Anesth 1989;14:251.

12. Chumney D, Nollinger K, Shesko K, Skop K, Spencer M, Newton RA. Ability of Functional Independence Measure to accurately predict functional outcome of stroke-specific population: Systematic review. Journal of Rehabilitation Research and Development; 2010: 47(1): 17.

13. Chan LY, Tsui MH, Leung TN. Guillain-Barrésyndrome in pregnancy. Acta Obstet Gynecol Scand. 2004;83(4):319.

14. Granger CV, Black T, Braun SL. Quality and outcome measures in Medical Rehabilitation. In: Braddom RL (edit), Physical Medicine \& Rehabilitation. Elseveir Saunders 2007; 8: 151-164.

15. Ottenbacher KJ, Smith PM, Illig SB, Linn RT, Ostir GV, Granger CV. Trends in length of stay, living setting, functional outcome, and mortality following medical rehabilitation. JAMA 2004; 292:1687..

16. Chung SM, Nissenbaum MM. Obstetrical paralysis. Orthop Clin North Am. 1975; 6(2):393.

17. Ng YS, Jung H, Tay SS, Bok CW, Chiong Y, Lim PAC. Results From a Prospective Acute Inpatient Rehabilitation Database: Clinical Characteristics and Functional Outcomes using the Functional Independence Measure. Ann Acad Med Singapore $2007 ; 36: 3$. 